\title{
Analisis Implementasi Sosialisasi Pemberian Asi Eksklusif Oleh Bidan Praktek Swasta (BPS) Di Kabupaten Bengkulu Selatan
}

\section{Analysis on the Implementation of Exclusive Breastfeeding Socialization by Private Practice Midwives in South Bengkulu District}

\author{
Lela Hartini ${ }^{1}$, Martha Irene Kartasurya ${ }^{2}$, Susi Herawati ${ }^{2}$ \\ ${ }^{1)}$ Akademi Kebidanan Muhammadiyah Madiun \\ ${ }^{2)}$ Fakultas Kesehatan Masyarakat, Universitas Diponegoro, Semarang
}

\begin{abstract}
Abstrak
Profil Dinas Kesehatan Kabupaten Bengkulu Selatan tahun 2008-2009 tidak mencantumkan data tentang cakupan ASI eksklusif. BPS tidak mempunyai SOP dalam melakukan pelayanan kebidanan. Salah satu tugas bidan adalah melakukan sosialisasi pemberian ASI eksklusif kepada ibu hamil, bersalin dan nifas serta masyarakat. Tujuan penelitian adalah untuk menganalisis implementasi sosialisasi dalam pemberian ASI eksklusif oleh Bidan Praktek Swasta (BPS) di Kabupaten Bengkulu Selatan.

Penelitian ini menggunakan metode kualitatif dan tehnik pengumpulan data adalah indepth interview. Informan utama yaitu 3 orang BPS wilayah perkotaan dan 2 orang BPS wilayah pedesaan, triangulasi dengan 5 orang kepala puskesmas, kasie gizi dan ketua IBI. FGD dilakukan pada 3 orang ibu dan 3 orang masyarakat (keluarga pasien) pada setiap BPS terpilih.

Hasil penelitian pada variabel implementasi sosialisasi pemberian ASI eksklusif masih terbatas pada penyuluhan individu serta tidak memiliki bahan-bahan penyuluhan. Pada variabel komunikasi antara kepala Puskesmas, Dinas Kesehatan dan ketua IBI terhadap BPS masih belum ada. Pada variabel sumberdaya (sarana prasarana) di BPS masih kurang menunjang keberhasilan program ASI eksklusif. Disposisi masih belum mendukung peningkatan cakupan ASI eksklusif, pada variabel struktur birokrasi tidak terdapat format pelaporan dari BPS ke Puskesmas dalam implementasi sosialisasi pemberian ASI eksklusif di Kabupaten Bengkulu Selatan.

Disarankan bagi Dinas Kesehatan membuat regulasi kebijakan dalam bentuk Surat Keputusan (SK) tentang pemberian ASI eksklusif dan membuat larangan BPS bekerjasama dengan perusahaan susu formula. Bagi kepala Puskesmas untuk melakukan supervisi dan monitoring ke BPS. Bagi BPS diharapkan agar meningkatkan frekuensi sosialisasi pemberian ASI eksklusif dan tidak bekerjasama dengan pabrik susu formula.
\end{abstract}

Kata kunci : Implementasi Sosialisasi ASI eksklusif, Bidan Praktek Swasta Referensi : $12(2001-2010)$

\begin{abstract}
Profile of South Bengkulu district health office 2008-2009 did not include data on exclusive breastfeeding coverage. Private practice midwives (BPS) did not have standard operating procedure $(S O P)$ in providing obstetric service. One of midwives duties was to provide exclusive breastfeeding socialization to pregnant women, childbearing mothers and community. The objective of this study was to analyze the implementation of exclusive breastfeeding socialization by BPS in South Bengkulu district.

This study applied qualitative method and using in-depth interview as data collection technique. The main informant was 3 private practice midwives in the city area and 2 private practice midwives in the rural area. Triangulation was done to 5 head of puskesmas, chief of nutritional
\end{abstract}


unit and head of Indonesian Midwifery Association (IBI). Focus group discussion was conducted to 3 mothers and 3 people in the community (family member of the patient) in each selected BPS. Results of the study showed that implementation of exclusive breastfeeding socialization variable was still limited to individual education and no education materials were provided. There was no communication among head of puskesmas, head of district health office and head of IBI towards BPS. BPS facilities were still insufficient to support the success of exclusive breastfeeding. Disposition had not supported exclusive breastfeeding coverage improvement. In the bureaucracy structure variable, there was no reporting format from BPS to puskesmas on exclusive breastfeeding socialization implementation in South Bengkulu district.

It was suggested to district health office to formulate regulation policy in the form of decree regarding exclusive breastfeeding and to forbid collaboration between BPS and infant formula companies. Head of puskesmas had to do supervision and monitoring to BPS. Private practice midwives were expected to improve the frequency of exclusive breastfeeding socialization and to avoid collaboration with infant formula companies.

Keywords : Exclusive Breastfeeding Socialization Implementation, Private Practice Midwives

Bibliography : $12(2001-2010)$

\section{Pendahuluan}

Modal dasar pembentukan manusia berkualitas dimulai sejak janin dalam kandungan dengan memberi nutrisi pada ibu hamil dilanjutkan pemberian ASI eksklusif setelah bayi dilahirkan yaitu memberikan ASI saja termasuk kolostrum tanpa memberikan makanan serta minuman tambahan kepada bayi sejak dilahirkan sampai berusia 6 bulan kecuali obat. ${ }^{1,2}$ Indikator meningkatnya derajat kesehatan dan kesejahteraan masyarakat salah satunya ditandai dengan menurunnya Angka Kematian Bayi (AKB). Millenium Development Goals (MDGs) pada tahun 2015 menargetkan terjadi penurunan angka kematian bayi menjadi dua pertiganya dari angka kematian bayi di tahun 1990 artinya kita harus menurunkannya dari 97 kematian bayi per 1.000 Kelahiran Hidup (KH) menjadi 32 kematian bayi per $1.000 \mathrm{KH}$. Pada tahun 2000 angka kematian bayi di Indonesia mencapai 35 per 1000 kelahiran hidup. ${ }^{3}$ Angka Kematian Bayi (AKB) di Provinsi Bengkulu tahun 2008 sebanyak 7,3 per 1000 kelahiran hidup, sedangkan di Kabupaten Bengkulu Selatan AKB pada tahun 2007 yang meninggal dunia 51 orang dari 3.215 kelahiran hidup (16,3 per 1000 kelahiran hidup), tahun 2008 berjumlah 42 orang dari $3.180 \mathrm{KH}(13,2$ per 1000 kelahiran hidup) dan pada tahun 2009 meningkat 50 dari $3.057 \mathrm{KH}(15,2$ per 1000 kelahiran hidup). Angka Berat Badan balita dibawah garis merah pada tahun 2007 di
Kabupaten Bengkulu Selatan yaitu 1,49\%, tahun $2008: 3,04 \%$ dan tahun $2009: 1,03 \%$.

Studi pendahuluan dilakukan oleh peneliti pada bulan Oktober 2010 dengan 10 orang bidan praktek swasta (BPS) di Kabupaten Bengkulu Selatan, diperoleh informasi bahwa 3 orang BPS mengatakan bahwa hanya pada ibu hamil primi gravida yang dilakukan sosialisasi tentang ASI eksklusif, 3 orang BPS mengatakan bahwa kadang-kadang ibu hamil yang melakukan Antenatal Care (ANC) diberikan informasi tentang ASI eksklusif dan 4 orang BPS mengatakan tidak memberikan sosialisasi tentang ASI eksklusif, 8 orang BPS juga mengatakan kadang-kadang sudah melaksanakan Inisiasi Menyusu Dini (IMD) dan 2 orang BPS tidak tahu tentang IMD, semua BPS memberikan susu formula kepada keluarga ibu yang ditolong persalinannya sebagai cadangan jika ASI kurang atau bayi tersebut rewel. Semua BPS tidak mempunyai SOP dalam melakukan pelayanan dan tidak pernah ada supervisi dari Dinas Kesehatan maupun Puskesmas kepada BPS.

Komunikasi dan koordinasi Program ASI eksklusif di Kabupaten Bengkulu Selatan masih belum jelas, berdasarkan penjelasan dari kepala Puskesmas di Kabupaten Bengkulu Selatan bahwa mereka tidak pernah diajak rapat/diskusi oleh Dinas Kesehatan atau instansi lain menyangkut program ASI eksklusif. Tidak ada alokasi yang jelas tentang pendanaan, maupun sarana dan prasarana yang 
disediakan untuk membantu pelaksanaan kelancaran sosialisasi, tidak ada sanksi atau reward terhadap cakupan ASI eksklusif.

\section{Metode Penelitian}

Penelitian ini menggunakan rancangan observasional dengan pendekatan kualitatif yang bermaksud untuk memahami fenomena tentang apa yang dialami oleh subyek penelitian dengan cara deskriptif. ${ }^{5}$ Tehnik pengumpulan data yang peneliti gunakan adalah wawancara mendalam (indepth interview) dan observasi. Menggunakan tehnik triangulasi sumber untuk mendapatkan data dari sumber yang berbeda-beda dengan tehnik yang sama yang sekaligus untuk menguji validitas data. $^{6}$

\section{Metode Pengumpulan Data}

1. Data Primer

Pengumpulan data primer dilakukan dengan cara :

a. Wawancara Mendalam

Wawancara terhadap BPS tentang sosialisasi pemberian ASI eksklusif dan wawancara untuk informan triangulasi dilakukan kepada kasie gizi, kepala Puskesmas dan ketua IBI. Hasil wawancara tersebut direkam dengan menggunakan tape recorder dan kemudian disajikan dalam bentuk transkrip hasil wawancara mendalam.

b. FGD (Focus Group Discussion)

Dilakukan pada ibu yang memiliki bayi usia kurang dari 6 bulan dan mendapatkan pelayanan ANC, INC, PNC di BPS yang terpilih, serta FGD juga dilakukan pada masyarakat dalam hal ini adalah keluarga pasien yang pernah diberikan pelayanan kebidanan pada BPS.

c. Observasi

Tehnik observasi dilakukan terhadap sarana prasarana implementasi sosialisasi pemberian ASI eksklusif di Bidan Praktik Swasta yang mendukung kelancaran pelayanan ASI eksklusif yaitu bahanbahan penyuluhan, protap dan alat bantu penyuluhan, dll. Pengumpulan data melalui tehnik observasi dilakukan dalam bentuk cheklist.

\section{Data Sekunder}

Data sekunder diperoleh dengan telaah dokuman dari laporan-laporan tentang pemberian ASI eksklusif

Subjek penelitian atau informan terpilih adalah 3 orang bidan praktek swasta mewakili daerah kota di Kabupaten Bengkulu Selatan yaitu: BPS di Kecamatan Kota Manna, Kecamatan Manna dan Kecamatan Pasar Manna, serta 2 orang bidan praktek swasta mewakili daerah pedesaan Kabupaten Bengkulu Selatan yaitu: BPS Kecamatan Pino Raya dan Kecamatan Bunga Mas Kabupaten Bengkulu Selatan. Sebagai informan triangulasi adalah Kasie gizi Dinas Kesehatan Kabupaten Bengkulu Selatan, 5 orang Pimpinan Puskesmas dari masingmasing kecamatan terpilih, dan Ketua IBI, serta 3 orang ibu yang memiliki bayi usia kurang dari 6 bulan dan 3 orang anggota masyarakat dalam hal ini keluarga pasien untuk setiap bidan di Kecamatan terpilih.

\section{Hasil}

Hasil penelitian pada variabel Implementasi sosialisasi pemberian ASI eksklusif masih terbatas pada penyuluhan individu serta tidak memiliki bahan-bahan penyuluhan. Pada variabel komunikasi dalam implementasi sosialisasi ASI eksklusif masih belum jelas. Sumber daya (sarana prasarana) masih kurang menunjang keberhasilan program ASI eksklusif. Disposisi masih belum mendukung peningkatan cakupan ASI eksklusif. Sedangkan pada variabel Struktur Birokrasi dalam implementasi sosialisasi pemberian ASI eksklusif di Kabupaten Bengkulu Selatan masih belum jelas.

Disarankan bagi Dinas Kesehatan membuat regulasi kebijakan dalam bentuk Surat Keputusan (SK) tentang pemberian ASI eksklusif dan membuat larangan BPS bekerjasama dengan perusahaan susu formula. Bagi kepala Puskesmas melakukan supervisi dan monitoring ke BPS. Bagi BPS diharapkan agar meningkatkan frekuensi sosialisasi pemberian ASI eksklusif dan tidak bekerjasama dengan pabrik susu formula 


\section{Pembahasan}

Implementasi Sosialisasi Pemberian ASI Eksklusif

\section{Pada saat Ante Natal Care (ANC)}

Hasil penelitian ini didapatkan bahwa kegiatan sosialisasi dalam pemberian ASI eksklusif masih kurang optimal hal ini dapat dilihat dari hampir semua BPS tidak terlalu memperhatikan tentang sosialisasi pemberian ASI pada pasien, padahal seharusnya bidan bisa lebih memfokuskan persiapan pemberian ASI eksklusif pada ibu tetapi pada kenyataannya kegiatan penyuluhan yang dilakukan BPS hanya sebatas penyuluhan individu saja dan kadang-kadang tidak menggunakan media maka tidak akan mampu mencapai hasil yang optimal. Seharusnya kegiatan sosialisasi pemberian ASI eksklusif yang harus dilakukan adalah sosialisasi dan penyuluhan yang meliputi pengertian ASI, tehnik menyusui, cara menyimpan ASI, manfaat ASI bagi bayi, keluarga, pemerintah, pentingnya colusterum, perawatan payudara dan mengatasi masalah-masalah menyusui yang disiapkan sedini mungkin sehingga ibu maupun keluarga betul-betul memahami dan bisa mempersiapkan sedini mungkin untuk mendukung pemberian ASI secara eksklusif pada bayinya karena itu suami maupun keluarga harus dilibatkan.,

\section{Pada saat Intra Natal Care (INC)}

Dari hasil penelitian diatas tentang implementasi pemberian ASI eksklusif dapat dianalisis bahwa semua BPS melakukan sosialisasi pemberian ASI eksklusif pada pasien dengan cara penyuluhan secara individu kepada pasien pada saat pasien melakukan ANC namun setelah bidan menolong persalinan semua bayi diberi susu formula meskipun kadang-kadang bukan bidan sendiri yang memberikan, hal ini dapat terjadi karena adanya motivasi yang diberikan oleh pabrik susu formula dengan memberikan reward dan imbalan kepada BPS sehingga BPS mau melakukan kerjasama dengan pabrik susu. Sebagaimana menurut teori GR Terry yang mengatakan bahwa motivasi adalah keinginan yang terdapat pada seseorang individu yang merangsangnya untuk melakukan tindakantindakan. Untuk dapat memotivasi pelaksana kebijakan dalam hal ini BPS maka pembuat kebikan harus mengetahui kebutuhan (needs) dan keinginan (wants) yang diperlukan BPS dari hasil pekerjaannya itu. Motivasi sangat dipengaruhi oleh faktor antara lain adanya kompensasi atau imbalan, merupakan faktor yang penting untuk meningkatkan prestasi kerja, motivasi dan kepuasan kerja adalah dengan pemberian kompensasi. ${ }^{8}$

\section{Komunikasi}

Dari hasil penelitian diatas dapat dianalisis bahwa selama ini masih kurang komunikasi dari kepala Puskesmas, kasie gizi dan ketua IBI terhadap Bidan Praktek Swasta dalam melaksanakan sosialisasi pemberian ASI eksklusif. Seharusya komunikasi merupakan sumber informasi yang sangat penting, dalam melakukan komunikasi ini sering ditemukan hambatan-hambatan antara lain karena pertentangan pendapat antara para pelaksana dan perintah yang dikeluarkan oleh pengambil kebijakan. ${ }^{9} \quad$ Edward mengidentifikasi enam faktor yang mendorong terjadinya ketidakjelasan komunikasi kebijakan yakni kompleksitas kebijakan, keinginan untuk tidak menggangu kelompok masyarakat, kurangnya konsensus mengenai tujuan kebijakan, masalah dalam memulai suatu kebijakan baru, menghindari pertanggungjawaban kebijakan, dan sifat pembentukan kebijakan pengadilan. ${ }^{9}$

\section{Sumber Daya (Dana,Sarana dan Prasarana)}

Dari hasil penelitian diatas dapat diketahui bahwa sumber daya (dana, sarana dan prasarana) di Kabupaten Bengkulu Selatan masih sangat terbatas sehingga BPS dalam melakukan implementasi sosialisasi ASI eksklusif masih relatif kurang maksimal. Tenaga pelaksana dalam sosialisasi pemberian ASI eksklusif terutama bidan praktek swasta tidak pernah mendapatkan pelatihan dari pemerintah untuk meningkatkan sumber daya manusia sehingga kemampuan dan kemauan mereka untuk meningkatkan cakupan ASI eksklusif menjadi tidak maksimal karena mereka sudah merasakan imbalan yang cukup besar dari promosi pabrik susu. Pada Standar Pelayanan Kebidanan (SPK) yang ke 15 dijelaskan pelayanan kebidanan kepada ibu dan bayi pada masa nifas tujuannya adalah memberikan pelayanan kepada ibu dan bayi sampai 42 hari setelah persalinan dan memberikan penyuluhan ASI eksklusif. ${ }^{10}$ 
Dalam melakukan implementasi sosialisasi pemberian ASI eksklusif sangat dipengaruhi oleh faktor komunikasi dan sumber daya sehingga diharapkan dapat meningkatkan cakupan ASI eksklusif di Kabupaten Bengkulu Selatan.

\section{Disposisi}

Dari hasil penelitian diatas dapat dilihat bahwa disposisi yaitu tentang sikap atau tanggapan bidan praktek swasta dan kepala Puskesmas, kasie kesga serta ketua IBI mengenai implementasi sosialisasi pemberian ASI eksklusif masih belum mendukung keberhasilan pemberian ASI eksklusif. Hal ini dapat disebabkan karena kendala dalam sosialisasi pemberian ASI eksklusif yang paling utama adalah gencarnya promosi susu formula di kalangan pelaksana implementasi sosialisasi pemberian ASI eksklusif, dan masih kurangnya perhatian dari pemerintah terutama Dinas Kesehatan Kabupaten Bengkulu Selatan, tidak adanya surat edaran maupun PP yang mendukung pemberian ASI eksklusif sehingga bidan pelaksana merasa lebih menguntungkan kalau melakukan kerjasama dengan pabrik susu formula karena tidak ada sanksi dari pembuat kebijakan. Seharusnya bidan praktek swasta dalam menghadapi gencarnya pemberian susu formula dapat melakukan hal-hal seperti : tidak menyimpan gambar yang berkaitan dengan susu formula, tidak memberikan susu formula kepada ibu menyusui, dan bila perusahaan mendatangi dan mencoba untuk memberikan susu formula cuma-cuma maka BPS harus menolak dan tidak mau bekerjasama. ${ }^{11}$

\section{Struktur Birokrasi}

Dari hasil penelitian ini dapat diketahui bahwa struktur birokrasi di Kabupaten Bengkulu Selatan masih belum jelas terhadap implementasi sosialisasi pemberian ASI eksklusif. Tidak adanya sosialisasi tentang SOP yang seharusnya dilakukan oleh kepala seksi gizi karena sesuai dengan tugas pokok kasie gizi yang merencanakan, melaksanakan, mengevaluasi serta melakukan koordinasi kegiatan yang berhubungan dengan ASI ekslusif. Menurut penelitian Ghana (2004) yang menunjukkan bahwa resiko kematian bayi dapat dicegah sekitar $22 \%$ jika disusui sebelum lewat 1 jam pertama usianya, jika pemberian ASI diberikan terlambat tapi masih kurang dari 24 jam maka sekitar $16 \%$ kematian bayi dapat dicegah. ${ }^{12}$ Pada saat melakukan implementasi masih adanya keterbatasan sumber-sumber yang dimiliki sehingga pelaksana kegiatan melakukan kegiatan dengan tidak maksimal. Pada dasarnya seluruh siklus hidup manusia memerlukan penanganan Kesehatan yang adekuat karena status Kesehatan pada usia neonatus dan bayi berpengaruh pada status Kesehatan pada tingkat usia selanjutnya. Jika menginginkan sumber daya manusia yang berkualitas, maka intervensi yang dilakukan harus sudah dimulai sejak dalam kandungan, kehamilan dan persalinan. Bayi yang kurang asupan gizi, terutama bagi bayi-bayi yang tidak mendapatkan ASI sama sekali akan menghasilkan bayi yang rentan terhadap penyakit, infeksi dan masalah pertumbuhan maupun perkembangan pada bayi.

Menurut teori Model implementasi George C. Edwards III implementasi kebijakan dipengaruhi oleh variabel struktur birokrasi, komunikasi, sumber daya dan disposisi yang saling berhubungan satu dengan yang lain karena jika salah satu faktor tidak berperan dengan baik maka akan sangat mempengaruhi pencapaian keberhasilan implementasi. ${ }^{9}$ Sehingga jika model implementasi kebijakan tersebut berperan dengan baik dapat meningkatkan cakupan pemberian ASI eksklusif di Kabupaten Bengkulu Selatan.

\section{Kesimpulan}

Pelaksanaan Implementasi sosialisasi pemberian ASI eksklusif oleh Bidan Praktek Swasta di Kabupaten Bengkulu Selatan sangat dipengaruhi oleh faktor komunikasi, sarana prasana, disposisi dan struktur birokrasi. Yang dibuktikan dengan hasil penelitian sebagai berikut :

a. Secara umum implementasi sosialisasi pemberian ASI eksklusif baik di BPS wilayah perkotaan maupun di BPS wilayah pedesaan tidak banyak perbedaan, semua masih belum berjalan dengan baik.

b. Secara umum komunikasi dalam implementasi sosialisasi ASI eksklusif masih belum jelas.

c. Secara umum Sumber Daya (dana,sarana dan Prasarana) dalam implementasi 
sosialisasi pemberian ASI eksklusif masih kurang mendukung.

d. Secara umum faktor disposisi atau sikap dalam implementasi sosialisasi pemberian ASI eksklusif masih belum mendukung keberhasilan peningkatan cakupan pemberian ASI eksklusif.

e. Secara umum peran struktur birokrasi dalam pelaksanaan sosialisasi pemberian ASI eksklusif masih belum jelas.

\section{Daftar Pustaka}

1. Depkes RI. Strategi Nasional Peningkatan Pemberian Air Susu Ibu. Jakarta: Depkes RI; 2008.

2. Suradi Rulina dan Kristina P. Tobing Hesti, Manajemen Laktasi, Cetakan kedua. Perinasia. Jakarta: 2004.

3. Depkes RI. Strategik Akselerasi Pencapaian Target MDGs 2015. Jakarta: 2008.

4. Depkes RI. Profil Dinas Kesehatan Provinsi Bengkulu. 2009.

5. Maleong. Metodologi Penelitian Kualitatif edisi revisi. PT Remaja Rosda Karya Bandung. Jakarta: 2008.

6. Bungin, Burhan. Metodologi Penelitian Kualitatif. Jakarta: Penerbit Raja Grapindo Prasaja; 2001.

7. Depkes RI. Manajemen Laktasi : Buku Panduan Bagi Bidan dan Petugas Kesehatan di Puskesmas. Jakarta: Direktorat Jendral Bina Kesehatan Masyarakat, Direktorat Gizi Masyarakat; 2001.

8. Mulyati. S. Strategi Sosialisasi Peningkatan Pemberian ASI (PP-ASI) eksklusif di Kota Bengkulu. Jogyakarta: 2005.

9. Agustino,Leo. Dasar-dasar Kebijakan Publik. Bandung: Penerbit CV Alfabeta; 2008.
10. Pengurus Pusat Ikatan Bidan Indonesia, Standar Pelayanan Kebidanan, cetakan ke-V. Mei 2005 Nursyamiah, Analisis Implementasi Program Pemberian ASI eksklusif di Puskesmas Wilayah Kota Semarang, Semarang 2009.

11. Proverawati.A \& Rahmawati.E. Kapita Selekta ASI dan Menyusui. Edisi I. Yogyakarta : Penerbit Moha Medika; 2010.

12. Depkes, RI. Ibu Rumah Tangga Selalu Memberikan Air Susu Ibu (ASI). Jakarta: Depkes RI; 2005. 